\title{
IMPACT OF DIABETES MELLITUS ON TREATMENT OUTCOME OF MULTIDRUG RESISTANT PULMONARY TUBERCULOSIS
}

\author{
Tariq Mahmood ${ }^{1}$, Arvind Kumar Verma², Kaleem Ahmad³, Sachi Satpathy4, Abida Akmal5, Ashish Kumar Gutpa ${ }^{6}$ \\ 1 Professor and Head, Department of Pulmonary Medicine, MLN Medical College, Allahabad, Uttar Pradesh, India. \\ ${ }^{2} 3^{\text {rd }}$ Year Junior Resident, Department of Pulmonary Medicine, MLN Medical College, Allahabad, Uttar Pradesh, India. \\ ${ }^{33}{ }^{\text {rd }}$ Year Junior Resident, Department of Pulmonary Medicine, MLN Medical College, Allahabad, Uttar Pradesh, India. \\ ${ }^{4}$ Ex Technical Advisor in Tuberculosis in The Union South East Asia Region, New Delhi, India. \\ ${ }^{5}$ Senior Consultant, ESI Hospital, Allahabad, Uttar Pradesh, India. \\ ${ }^{6}$ Associate Professor, Department of Pulmonary Medicine, UPUMS, Saifai, Itawa, Uttar Pradesh, India.
}

\begin{abstract}
BACKGROUND
ABSTRACT

Multiple studies have indicated that patients of pulmonary tuberculosis with diabetes mellitus may experience poor outcome. Emergence of Multidrug Resistant-TB has further complicated the situation, as its management may be challenging in presence of diabetes. There is a paucity of data on effect of diabetes on outcome of MDR-TB in Indian context.

The study aimed to assess the effect of Diabetes Mellitus on mean time for sputum culture conversion and treatment outcome in patients of Multidrug Resistant Pulmonary Tuberculosis.
\end{abstract}

\section{MATERIALS AND METHODS}

The present observational cross-sectional study was conducted at Drug Resistant-TB centre, SRN Hospital, MLN Medical College, Allahabad. 144 diagnosed patients of MDR-TB were treated with Category IV DOTS and were retrospectively analysed for the effect of DM as a comorbidity on their outcome on treatment completion. The diagnosis of Diabetes Mellitus and treatment outcomes were defined as per WHO guidelines.

\section{RESULTS}

Out of 144 MDR-TB patients, 13 (9.03\%) had co-existing Diabetes Mellitus. Patients having MDR-TB with Diabetes had longer sputum culture conversion time (131.4 \pm 40.99 vs. $118.72 \pm 41.54$ days, $\mathrm{p}=0.358)$ compared to MDR-TB patients without diabetes. They also had 2.75 times higher odds of death than patients in non-diabetic group (53.85\% vs. 30.47\%, 95\% confidence interval [CI] 0.869 to 8.717). Non-diabetics had 1.84 times higher odds of culture negativity at 6 months $(54.26 \%$ vs. $38.46 \%$, CI=0.57 to 5.91 ) and 1.73 times odds of successful treatment ( $44.53 \%$ vs. $30.77 \%, \mathrm{CI}=0.51$ to 5.91 ) compared to diabetic patients. $12.5 \%$ patients defaulted on treatment in non-diabetic group, while diabetic group had no default. 15.38\% patients failed treatment in diabetic group compared to $12.5 \%$ in non-diabetic group ( $\mathrm{p}=0.667)$. Outcome of 3 patients was not known, since they were transferred out.

\section{CONCLUSION}

Diabetes Mellitus as a comorbidity was associated with longer culture conversion time, decreased success rate, higher treatment failure and higher death rate among patients of MDR-TB, but the results were not found to be statistically significant which may be due to small sample size in the MDR-TB with diabetes group.

\section{KEY WORDS}

MDR TB, Diabetes Mellitus, Pulmonary Tuberculosis, Sputum Conversion.

HOW TO CITE THIS ARTICLE: Mahmood T, Verma AK, Ahmad K, et al. Impact of diabetes mellitus on treatment outcome of multidrug resistant pulmonary tuberculosis. J. Evolution Med. Dent. Sci. 2018;7(22):2674-2677, DOI: 10.14260/jemds/2018/602

\section{BACKGROUND}

Multiple studies have indicated that patients of pulmonary tuberculosis with diabetes mellitus (DM) may experience poor outcome. Emergence of Multidrug Resistant tuberculosis (MDR-TB) has further complicated the situation, as its management may be challenging in presence of diabetes. In the early 20th century the effect of DM on TB was of great concern to investigators, but this was neglected

'Financial or Other Competing Interest': None

Submission 29-03-2018, Peer Review 11-05-2018,

Acceptance 17-05-2018, Published 28-05-2018.

Corresponding Author:

Dr. Tariq Mahmood,

L-6, Medical College Campus,

MLN Medical College, Allahabad-211001,

Uttar Pradesh, India.

E-mail: mlnmctariqmahmood@gmail.com

DOI: $10.14260 /$ jemds $/ 2018 / 602$

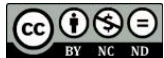

in the second half of the $20^{\text {th }}$ century with the emergence of proper treatment for both diabetes and pulmonary tuberculosis. 1,2 The link of DM and TB is more prominent in developing countries, where $\mathrm{TB}$ is endemic and the prevalence of Diabetes is rising. In recent decades with the increasing prevalence of TB, particularly Multidrug-Resistant TB (MDR-TB) and DM cases in the world, the relationship is re-emerging as a significant public health problem. ${ }^{3}$

There is a paucity of data on effect of diabetes on outcome of MDR-TB in Indian context. Globally, in 2016 an estimated $4.1 \%$ of new cases and $19 \%$ of previously treated cases had MDR/ RR-TB. In 2016 there were 600,000 new cases with resistance to rifampicin (RRTB), the most effective first-line drug, of which 490,000 had multidrug-resistant TB (MDRTB). Almost half (47\%) of these cases were in India, China and the Russian Federation. 4 Recently, along with the convergence of the diabetes mellitus (DM) and TB epidemics, the high prevalence of DM among MDR-TB 
patients is a serious cause for concern with a range of $10 \%$ $23 \%$ of MDR-TB patients having DM.5-8

Diabetes triples a person's risk of developing tuberculosis. About $15 \%$ of TB cases globally may be linked to diabetes. TB can temporarily cause impaired glucose tolerance, which is a risk factor for developing diabetes. About 422 million people worldwide were living with diabetes in 2014. In 2014, the global prevalence of diabetes was estimated to be $8.5 \%$ among adults aged $18+$ years. In 2012, diabetes was the direct cause of 1.5 million deaths. WHO projects that diabetes will be the 7th leading cause of death in 2030. In 1980, diabetes prevalence was highest in high-income countries, now it is similar in both high- and low-income countries. ${ }^{9}$

\section{Aims and Objectives}

- To assess the effect of diabetes on mean time for sputum culture conversion in patients of MDR-TB.

- To assess the effect of diabetes on treatment outcome in patients of MDR-TB.

\section{MATERIALS AND METHODS}

This retrospective observational study of Drug-Resistant TB Centre was conducted in SRN Hospital, MLN Medical College, Allahabad, India. A total of 144 diagnosed patients of MDR-TB under Programmatic Management of Drug-Resistant Tuberculosis (PMDT), registered on Category-IV DOTS between March 2013 and January 2014 were retrospectively analysed for the effect of DM as a comorbidity on: - Mean sputum conversion time and treatment outcome on completion.

\section{Inclusion Criteria}

1. Diagnosed patients of MDR-TB under PMDT by CBNAAT.

2. Aged above 20 years.

\section{Exclusion Criteria}

Patients were excluded from the study for any of the following conditions-

1. Pregnancy.

2. HIV infection.

3. Connective tissue disorders.

4. Chronic renal failure.

5. Chronic liver disease.

6. Malignancies on long-term steroid or cytotoxic drug therapy.

7. Chronic alcoholic.

\section{Statistical Analysis}

Chi-square test and independent ' $\mathrm{t}$ ' test were used for statistical analysis. 95\% Confidence Interval of the parameters were also calculated. All statistical measurements were done using $\mathrm{R}$ version 3.1.2

\section{RESULTS}

Total number of patients enrolled in the study: 144. Out of 144 MDR-TB patients were 13 (9.03\%), who had co-existing Diabetes Mellitus.

\begin{tabular}{|c|c|c|c|}
\hline Characteristics & $\begin{array}{c}\text { MDR-TB } \\
\text { with DM }\end{array}$ & $\begin{array}{c}\text { MDR-TB } \\
\text { without DM }\end{array}$ & $\begin{array}{c}\text { P- } \\
\text { value }\end{array}$ \\
\hline No. of Patients (\%) & $13(9.03 \%)$ & $131(90.97 \%)$ & \\
\hline Mean Age (In Years) & $38.61 \pm 12.11$ & $30.83 \pm 12.66$ & 0.0357 \\
\hline Sex & $12 \mathrm{M} / 1 \mathrm{~F}$ & $96 \mathrm{M} / 35 \mathrm{~F}$ & \\
\hline $\begin{array}{c}\text { Mean Time for Culture } \\
\text { Conversion (In Days) }\end{array}$ & $131.4 \pm 40.99$ & $118.72 \pm 41.54$ & 0.358 \\
\hline $\begin{array}{c}\text { Table 1. Comparison of Demographic and Clinical } \\
\text { Characteristics in MDR-TB Patients with and without } \\
\text { Diabetes Mellitus }\end{array}$ \\
\hline
\end{tabular}

Patients having MDR-TB with diabetes had longer sputum culture conversion time $(131.4 \pm 40.99$ vs. $118.72 \pm 41.54$ days) as compared to patients without diabetes. On applying $\mathrm{T}$-Test between these two groups, the p-value is 0.0357 which is statistically significant.

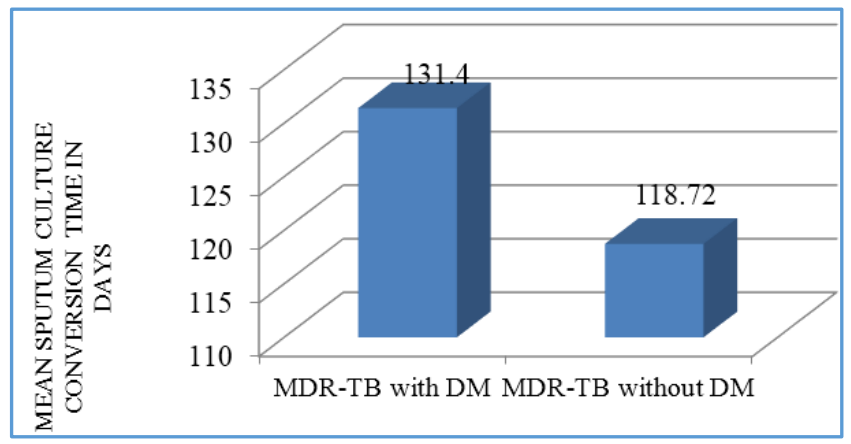

\begin{tabular}{|c|c|c|c|c|}
\hline Outcome & $\begin{array}{l}\text { MDR-TB } \\
\text { with DM }\end{array}$ & $\begin{array}{c}\text { MDR-TB } \\
\text { without } \\
\text { DM }\end{array}$ & \begin{tabular}{|c|} 
Odds Ratio \\
(95\% Confidence \\
Interval)
\end{tabular} & $\begin{array}{c}\text { P- } \\
\text { value }\end{array}$ \\
\hline $\begin{array}{c}\text { No. of } \\
\text { patients } \\
\text { who are } \\
\text { culture } \\
\text { negative at } \\
\text { the end of } 6 \\
\text { months (\%) }\end{array}$ & $\begin{array}{c}5 \\
(38.46 \%)\end{array}$ & $\begin{array}{c}70 \\
(54.26 \%)\end{array}$ & $\begin{array}{c}1.835 \\
(0.57-5.91)\end{array}$ & 0.31 \\
\hline $\begin{array}{c}\text { Favourable } \\
\text { outcome } \\
\text { (Cured + } \\
\text { Treatment } \\
\text { completed) }\end{array}$ & $\begin{array}{c}4 \\
(30.77 \%)\end{array}$ & $\begin{array}{c}57 \\
(44.53 \%)\end{array}$ & $\begin{array}{c}1.733 \\
(0.508-5.914)\end{array}$ & 0.38 \\
\hline $\begin{array}{c}\text { Died during } \\
\text { treatment }\end{array}$ & $\begin{array}{c}7 \\
(53.85 \%)\end{array}$ & $\begin{array}{c}39 \\
(30.47 \%)\end{array}$ & $\begin{array}{c}2.75 \\
(0.869-8.7171)\end{array}$ & 0.08 \\
\hline Default & 0 & $\begin{array}{c}16 \\
(12.5 \%)\end{array}$ & $\begin{array}{c}0.259 \\
(0.014-4.57)\end{array}$ & 0.356 \\
\hline Failure & $\begin{array}{c}2 \\
(15.38 \%)\end{array}$ & $\begin{array}{c}16 \\
(12.5 \%)\end{array}$ & $\begin{array}{c}1.307 \\
(0.265-6.439)\end{array}$ & 0.742 \\
\hline
\end{tabular}

The odds of culture negativity at 6 months was 1.84 times higher in non-diabetic group as compared to diabetic group (54.26\% vs. $38.46 \%, \mathrm{CI}=0.57$ to 5.91 ). On applying T-Test between these two groups, the p-value is 0.31 which is statistically not significant. 


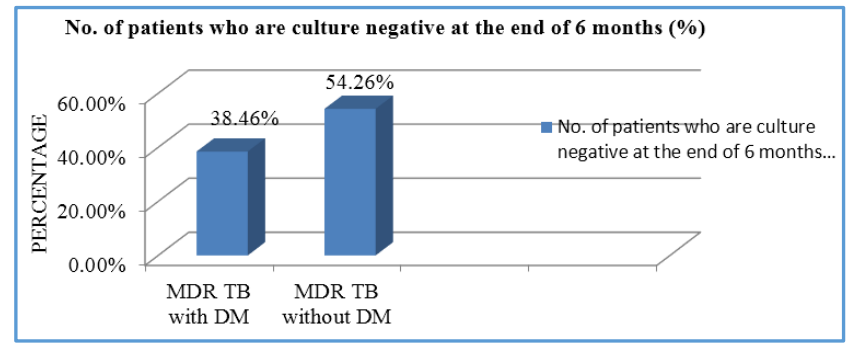

The odds of successful treatment were 1.73 times higher in non-diabetic group compared to diabetic group (44.53\% vs. $30.77 \%, \mathrm{CI}=0.51$ to 5.91 ). On applying $\mathrm{T}$-Test between these two groups, the p-value is 0.38 which is statistically not significant.

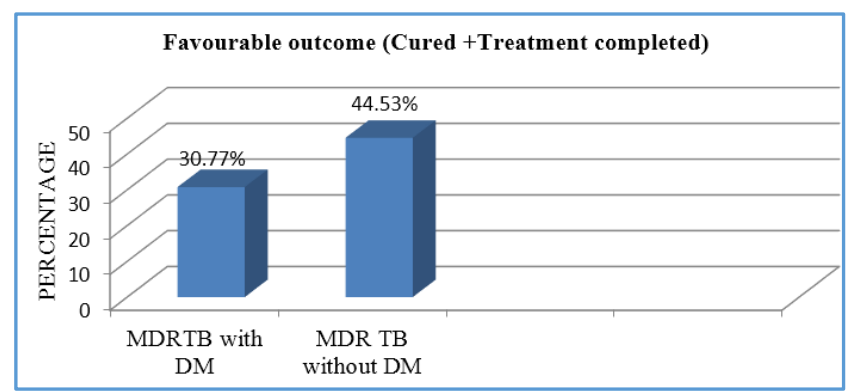

The odds of death in patients with diabetes was 2.75 times higher than patients without diabetes $(53.85 \%$ vs. $30.47 \%, 95 \% \mathrm{CI}=0.869$ to 8.717$)$. On applying $\mathrm{T}$-Test between these two groups, the p-value is 0.08 which is statistically not significant.

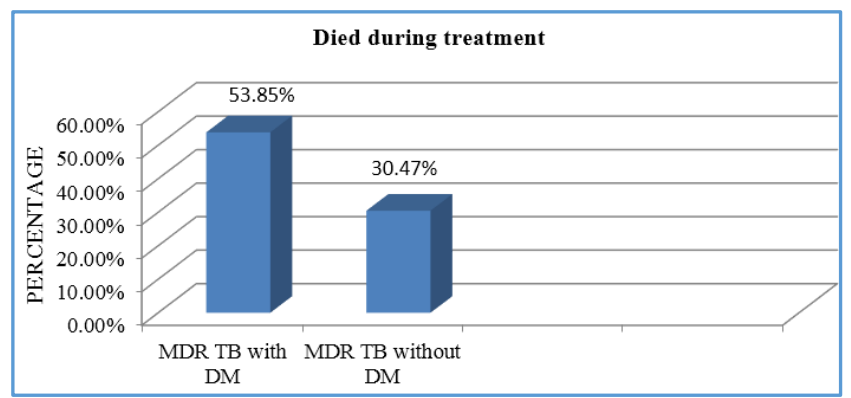

$12.5 \%$ patients defaulted on treatment in non-diabetic group, while diabetic group had no defaults. On applying TTest between these two groups, the p-value is 0.356 which is statistically not significant.

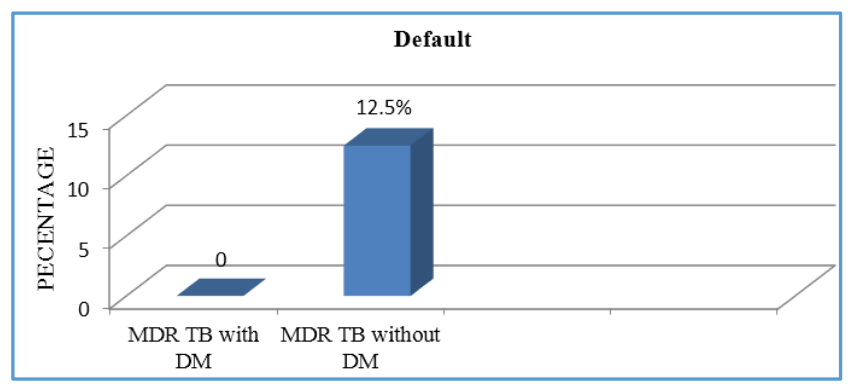

$15.38 \%$ patients failed treatment in diabetic group compared to $12.5 \%$ in non-diabetic. On applying T-Test between these two groups, the p-value is 0.742 which is statistically not significant.

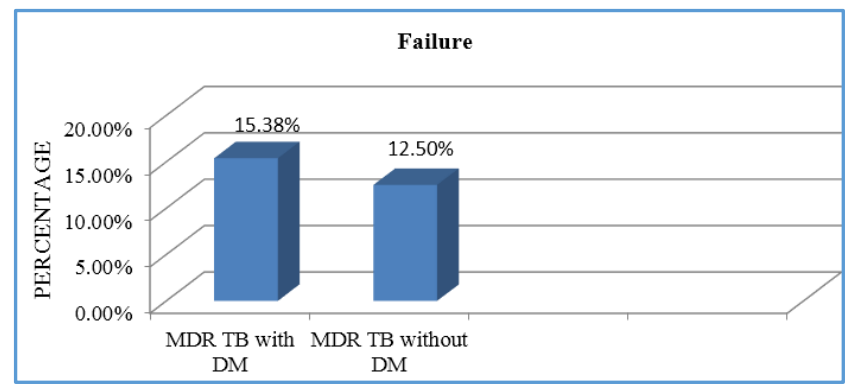

The number of patients who turned out to be XDR were $7.69 \%$ in diabetic group and $3.12 \%$ in non-diabetic group). On applying T-Test between these two groups, the p-value is 0.381 which is statistically not significant.

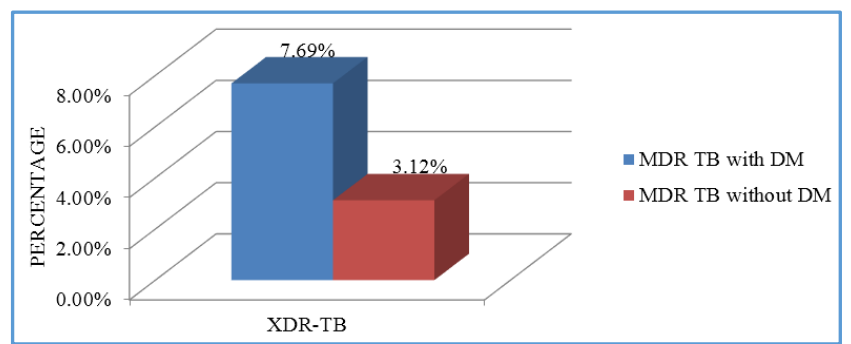

Outcome of 3 patients was not known since they were transferred out.

\section{DISCUSSION}

1. The growing prevalence of TB-DM comorbidity worldwide has provided a new challenge to clinical management and health systems control strategy 34 . It was observed that patients who have DM complicated with TB often experience delayed sputum culture conversion, increased risk of death and recurrence. ${ }^{10,11-13}$

2. The reasons for a higher MDR rate in patients with TBDM comorbidity are not thoroughly understood; however, they may differ by different MDR type (primary or secondary). The combination of impaired immune system in DM and bacterial genetics might be a reasonable explanation for primary MDR. It has been reported that poor glucose control is often associated with dysfunction of phagocytosis, reactive oxygen species (ROS) production, chemotaxis and T-cell reaction in DM patients. ${ }^{14}$

- Earlier studies had shown that proportion of cases of MDR-TB was significantly higher in patients with coexisting diabetes; however, recent study showed no such association, but concomitant MDR-TB and DM may result in delayed sputum culture conversion and poor treatment outcomes as indicated by our study. 15

- Findings of our study were also supported by the study done by Young Ae Kang et al (2013), who also found diabetes to be a common comorbid condition among MDR-TB patients with a negative impact on treatment outcome. Also, in patients undergoing treatment for MDR-TB, DM was independently associated with an increased risk of both treatment failure and death. 16 
- Bashar et al reported an increased risk of MDR-TB and relapse with resistant strains among diabetic patients. 15

\section{CONCLUSION}

- Diabetes as a comorbidity was associated with longer culture conversion time, decreased success rate, higher treatment failure and higher death rate among patients of MDR-TB.

- But in our study the results were not found to be statistically significant, which may be due to small sample size in the MDR-TB with diabetes group.

\section{REFERENCES}

[1] World Health Organization. Guidelines for the programmatic management of drug-resistant tuberculosis. WHO/HTM/2006.361. Geneva: The World Health Organization, 2006.

[2] World Health Organization. Global tuberculosis report 2015. Report No. HO/HTM/TB/2053.11. Geneva: The World Health Organization, 2015.

[3] Ruslami R, Aarnoutse RE, Alisjahbana B, et al. Implications of the global increase of diabetes for TB control and patient care. Trop Med Int Health 2010;15(11):1289-99.

[4] World Health Organization. Global Tuberculosis Report 2017.

[5] Singh R, Gothi D, Joshi JM. Multidrug resistant tuberculosis: role of previous treatment with second line therapy on treatment outcome. Lung India 2007;24:54-7.

[6] Aragon J, Litonjua A, Tupasi T, et al. Prevalence of type 2 diabetes among multi-drug resistant tuberculosis (MDR-TB) patients seen in Makati Medical Center under the directly observed therapy plus (DOTS PLUS) program. Philippine Journal of Internal Medicine 2003;41:7-10.

[7] Tanrikulu AC, Hosoglu S, Ozekinci T, et al. Risk factors for drug resistant tuberculosis in southeast Turkey. Trop Doct 2008;38(2):91-3.
[8] Garcia F, Solis J, Calderon J, et al. Prevalence of diabetes mellitus and related risk factors in an urban population. Revista de la Sociedad Peruana de Medicina Interna 2007;20:90-4.

[9] www.who.int/tb/areas-of-work/treatment/riskfactors/en/.

[10] Singla R, Khan N, Al-Sharif $\mathrm{N}$, et al. Influence of diabetes on manifestations and treatment outcome of pulmonary TB patients. The International Journal of Tuberculosis and Lung Disease: The official Journal of the International Union against Tuberculosis and Lung Disease 2006;10(1):74-9.

[11] Baker MA, Harries AD, Jeon CY, et al. The impact of diabetes on tuberculosis treatment outcomes: a systematic review. BMC Medicine 2011;9:81.

[12] Leung CC, Lam TH, Chan WM, et al. Lower risk of tuberculosis in obesity. Archives of Internal Medicine 2007;167(12):1297-304.

[13] Mi F, Tan S, Liang L, et al. Diabetes mellitus and tuberculosis: pattern of tuberculosis, two-month smear conversion and treatment outcomes in Guangzhou, China. Tropical Medicine \& International Health 2013;18(11):1379-85.

[14] Nijland HM, Ruslami R, Stalenhoef JE, et al. Exposure to rifampicin is strongly reduced in patients with tuberculosis and type 2 diabetes. Clinical Infectious Diseases: an official publication of the Infectious Diseases Society of America 2006;43(7):848-54.

[15] Bashar M, Alcabes P, Rom WN, et al. Increased incidence of multidrug-resistant tuberculosis in diabetic patients on the Bellevue Chest Service, 1987 to 1997. Chest 2001;120(5):1514-9.

[16] Kang YA, Kim SY, Jo KW, et al. Impact of diabetes on treatment outcomes and long-term survival in multidrug-resistant tuberculosis. Respiration 2013;86(6):472-8. 